\title{
Religious Involvement Effects on Mental Health in Chinese Americans
}

\author{
$\mathrm{Bu}$ Huang, $\mathrm{PhD}$ \\ Bastyr University, Kenmore, Washington, USA \\ E-mail: buhuang@gmail.com \\ Hoa B. Appel, PhD, MPH \\ Minority Achievers Program, Everett, Washington, USA \\ E-mail: hbappel@gmail.com \\ Amy L. Ai, PhD \\ Florida State University, Tallahassee, Florida, USA \\ E-mail: aai@fsu.edu \\ Chyongchiou Jeng Lin, $\mathrm{PhD}$ \\ University of Pittsburgh, Pittsburgh, Pennsylvania, USA \\ E-mail: CJLIN@pitt.edu
}

Received: October 24, $2011 \quad$ Accepted: December 2, $2011 \quad$ Published: January 1, 2012

doi:10.5539/ach.v4n1p2

URL: http://dx.doi.org/10.5539/ach.v4n1p2

The study has been supported by a grant from the Pittsburgh Center for Race and Social Problems. The opinions expressed in this article are those of the authors and do not necessarily reflect the views of this organization.

\begin{abstract}
Faith has been shown to serve a protective role in the mental health of African Americans and European Americans. However, little research has examined whether any association exists in Asian Americans. Using the National Latino and Asian American Study dataset, we examined the effect of religious attendance on the mental health of Asian Americans in the United States. The present study focused on Chinese Americans because they are the largest Asian American group. The results revealed that almost $80 \%$ of the respondents were foreign-born and that their English proficiency had a positive association with their self-rated mental health. Being male correlated significantly to higher levels of mental health self-rating. After controlling for known predictive variables, such as demographics, cultural and immigration variables, more frequent religious attendance significantly predicted higher self-rating of mental health. These findings suggest that faith may have a unique protective role in Chinese Americans' mental health.

Keywords: Mental health, Religious attendance, Religious involvement, Chinese Americans, Self-rating, NLAAS

\section{Introduction}

The population of Chinese Americans consists of immigrant descendants or new immigrants from various regions in Asia and other parts of the world. In the 19th century, the first major influx of Chinese arrived in the United States (US). This first group, comprising mostly farmers, emigrated from Southern China to help build US railroads (Chen, 1940). After the railroads were built, however, some laborers were forced out of the US and the remaining population experienced various degrees of discrimination, including violence and the denial of citizenship.
\end{abstract}


Responding to an anti-Chinese lobby, Congress passed the Chinese Exclusion Law in 1882 to ban the Chinese labor force (Chan, 1991). During the $20^{\text {th }}$ century, the population of Chinese Americans increased to three million which was slightly more than the number of Filipino Americans (US Census, 2004). The numbers of each group were similar, notwithstanding the much larger population of China, because of the long-term exclusion of Chinese immigrants.

Growing empirical evidence suggests that faith factors (factors pertaining to religiousness and spirituality) are a part of cultural identity and a meaning-making framework (Cohen and Hill, 2007), which can function as a protective factor for mental health (Pargament, Magyar-Russell, and Murray-Swank, 2005) or as a resource in coping with difficult issues (e.g., Coruh, Ayele, Pugh, and Mulligan, 2005; Fiala, Bjorck, and Gorsuch, 2002; Galanter, 2006; George, Ellison, and Larson, 2002; Koenig, McCullough, and Larson, 2001; Pargament, 1997; Pargament, Koenig, and Perez, 2000; Powell, Shahabi, and Thoresen, 2003; Smith, McCullough, and Poll, 2003; Townsend, Kladder, Ayele, and Mulligan, 2002). Most studies have drawn on evidence of faith and mental health from mainstream populations (e.g., European or African Americans holding Judeo-Christian faiths) with little attention to Asian Americans. This study examines Chinese Americans' religious practices and their effects on mental health. We focus on Chinese Americans because they are not only a diverse and unique population, but also the largest group of Asian Americans.

\subsection{The diverse faith held by Chinese Americans}

The lack of attention to the Asian American faiths has produced a significant gap in literature in the face of the rapid growth of the Asian American population (Ai, Bjorck, Huang, and Appel, in press; Passel and Cohn, 2008). Chinese Americans, like any other Americans, are of diverse religious and spiritual faiths (Ai et al., in press). Besides Asian-born beliefs, the faiths of Chinese Americans include mainstream religion and spirituality (i.e., Christianity, Islam, and Judaism). Yang (1999) suggested that one third of Chinese Americans are Christians, a much higher percentage than that of Chinese living in Asia. Many Chinese Americans converted to Christianity after immigrating to the US. Others brought their Christian faith with them to the US (Fong, 2000). Some may adhere to mainstream monotheist religions (Christianity, Islam, Judaism) while keeping aspects of their Asian-born faiths (Confucianism, Taoism, Buddhism) in unique multi-faith systems (Bjorck, Cuthbertson, Thurman, Lee, 2001; Bjorck, Lee, and Cohen, 1997).

Taoism, perhaps the least organized religion in the world, attributing no human nature to its divinity (Ai, 2006), is more cosmological and philosophical than religious. This contrasts with Western religions Christianity. Its doctrine, Tao Te Ching, delineates the divine link of humans. It also presents no afterlife reward based good deeds and practices performed during life, in contrast to Buddhism with its doctrine of reincarnation (Ai, 2000). Rather, Taoism follows an intuitive and dialectical inquiry into universal law, the nature of $D a o$, and especially patterns of ultimate changes driven by underlying energetic force (Ai, 2010).

If Chinese descendents see Taoism as a naturalistic faith, then they might view Confucianism as a humanistic faith. Confucianism keeps a respectable distance from gods and ghosts centering instead on a secular, moralistic and rational component of society, human relations, and guiding ethics (Ai et al., in press; Ai and McCormick, 2010; Peterson and Seligman, 2004). Confucian doctrine, Analects, promotes deep mutual respect as an appropriate interpersonal feeling among fellow humans, compared to a group of ritualistic actions, $L i$ (Ai et al., in press; Woodruff, 2001). In the Confucian view, ancestors' spirits may affect their descendants' lives in such ways as promoting learning and family honor. Ancestors are a part of their worship. Nevertheless, such spirits are primarily symbolic rather than literal, in contrast to spirits in certain African and South-American cultures, which are believed to occupy space (Ai and McCormick, 2010).

Buddhism, especially its Zen version (in the Chinese tradition of Ch'an), offers psychology and wisdom concerning human suffering in the forms of death, disability, illness, and aging (Ai, 2000) and serves disadvantaged Chinese descendants by providing inner peace and a sense of self-worth (Ai et al., in press). In Americanizing the Buddha, Buddhism challenges the prevailing world view of religion which lies mainly in the areas of humanity's spiritual relationships (Ai, 2000; Verhoeven, 1998). Rather than seeking a loving relationship with God, as Christians do, Buddhists approach the spiritual eternity through meditative practice, companionship among people and enlightenment from the disparity in the present life to infinite being (Groth-Marnat, 1992). Given different functions of Confucianism, Taoism, and Buddhism in the Chinese psychology, individuals may integrate various faiths into their lives based on their stages of life: pursuing education and peak achievement, approaching retirement, return to nature, and coping with late life suffering (Ai et al., in press). With this background of spiritual flexibility, Chinese Americans could easily integrate their Asian-born religious tradition with such mainstream monotheist religions as Christianity, Judaism, or Islam (Ai et al., in press). 
Many of the first Chinese immigrants to the US were followers of Hong Xiuquan, a Chinese Christian prophet who led the Taiping rebellion against the Manchu dynasty (Chen, 1940; Fong, 2000; Spence, 1996). Approximately one third of Chinese Americans are Christians (Yang, 1999), in contrast to a much smaller number of their counterparts in Asia. Jews were invited to China in the tenth century (Humphrey, 1982) and might have entered as early as the first century (Neubauer, 2009). In history, the impact of the Jews was extended through interracial marriage and building synagogues in central China. After World War II, some of their descendants moved to the US, along with Asian Americans who converted through marriage, and today constitute a small but significant part of the American Jewish community (Humphrey, 1982).

\subsection{Mental health of Chinese Americans and the role of religion}

The World Health Organization (WHO) predicts that by 2020, major depression will be one of the leading contributors to the global burden of disease (Murray and Lopez, 1996). Previous studies suggest that Asian immigrants generally have lower rates of major depression than do US-born Asians (Sue A., Sue D., Sue L., and Takeuchi, 1995; Takeuchi et al., 1998). In their cultures, however, somatic symptoms of mental health problems such as frequent backaches and headaches are culturally accepted (Herrick and Brown, 1998), which may lead to under-diagnosis of such problems.

Chinese immigrants who immigrated after 20 years of age are at least one and a half times more likely to experience major depression than are those who immigrated before age 20 (Takeuchi et al., 1998). Chinese Americans who lack social support rate their health as poor and experience high levels of life stress, are also at an increased risk to experience depression (Hwang, Myers, and Takeuchi, 2000). Taoism, Confucianism, and Buddhism all contain tenets regarding the integration of physical, mental, and spiritual health. This is in contrast to western cultures, which consider them to be separate and distinct areas of health (Ai, 2000; 2010). Unlike Western medicine, the traditional Chinese medicine brought to America by Chinese immigrants links emotional health with the healthy function of each organ. According to this belief, certain organs host specific types of spiritual and mental health in each individual (Ai, 2010). This could be one of the reasons why Chinese have high somatization rates according to mainstream mental health providers. It is relevant, therefore, to examine the effect of Chinese Americans' religious involvement on their mental health.

As part of a few Asian American studies, Guest (2003) argued that Chinese churches have become a major source of support, bridged cross-cultural gaps, and offered a sense of ethnic community for Chinese Americans in New York. An exploratory study by Lee and Chan (2009) showed that religious/spiritual coping plays an important role in life changes in older Chinese American immigrants. Also, Confucian beliefs may help explain why Chinese Americans are reluctant to donate their organs: An intact body shows respect for one's ancestors (Lam and McCullough, 2000). Whereas these few studies are limited in scope and sample size, they do suggest that religiousness is a construct worth investigating when considering factors affecting mental health in Chinese Americans. Factors which pertain to religiousness and spirituality may function as protective factors (Pargament et al., 2005) and as a resource in coping with physical and mental health issues (Ai et al., 2010; Ai, Hopp, Tice, \& Koenig, in press; Coruh et al., 2005, George et al., 2002). Ai et al. (in press) have found that religious attendance, but not religious coping, was associated with better mental health overall for Asian Americans.

Asian Americans have become a significant subgroup in the US, constituting 4.3\% of the total population, and this figure is projected to triple by the year 2050 (US Census, 2004). Given that Asian Americans represent a rapidly growing minority population, the omission of research on their religious involvement has become increasingly problematic. One reason for the lack of research in Asian Americans and religion may be attributed to their inherent cultural, socioeconomic and ideological diversity within this multiethnic group (Furuto and Murase, 1992). To address this gap, this study examined the relationship of religious involvement and mental health in Chinese Americans, specifically measured with self-reported mental health using the data from National Latino and Asian American Study (NLAAS). Hierarchical regression analyses were conducted to evaluate whether their religious involvement was associated with better self-reported mental health above and beyond that of demographics and some known predictors (e.g., demographics, acculturation). Based on previous findings (Ai et al., in press), we hypothesized that religious attendance predicts better self-reported mental health.

\section{Methods}

\subsection{Data source}

The NLAAS questionnaire was available in six languages (English, Spanish, Mandarin, Cantonese, Tagalog, and Vietnamese) and sampling procedure for the NLAAS was previously documented and weights were developed to correct for sampling bias (Alegria et al., 2004; Heeringa et al., 2004). The total sample size of the NLAAS is 4649, including 2554 Latinos and 2095 Asian Americans. This national study found $28.7 \%$ of the Asian sample to be 
Chinese Americans. In this analysis, we included all Chinese Americans in the database $(n=600)$.

\subsection{Measures and variables}

The data set included an assessment of social demographics, mental health screening and diagnosis variables, service usage and evaluations and acculturation and immigration items, among others.

\subsection{Outcome variables}

For our dependent variable, we used self-rating of mental health. The respondents were asked: "How would you rate your overall mental health -excellent, very good, good, fair, or poor?" The scale was coded from 1-5, with 1 meaning poor and 5 meaning excellent.

\subsection{Predictor of major interest}

We used religious attendance as a predictor in regression models. Religious affiliation was assessed under the demographic section of the survey. Respondents were asked: "What is your religious preference?" These responses were coded and entered into the NLAAS as Protestantism, Catholicism, Other religion, and No Religion. Unfortunately, no information in the public database was given that specified other faiths, such as Buddhism, Hinduism, Islam, or Judaism.

Religious attendance was assessed with frequencies. Respondents who had identified with religious affiliation were asked about service attendance: "How often do you attend religious services?" The answer was coded 1-5 (1 $=$ never, 2 = less than once a month, $3=$ once to three times $a$ month, $4=$ about once $a$ week, $5=$ more than once $a$ week). For respondents who self-identified with no religion, the attendance was coded as never.

\subsection{Covariates}

Based on literature (Gee, Spencer, Chen, Yip, and Takeuchi, 2007b), we selected two sets of potential control variables in our regression model to predict the mental health of Chinese Americans.

The first set of covariates included five Demographic and Socioeconomic Variables. First, gender was coded dichotomously (female $=0$, male $=1$ ). Second, age was assessed with years (ranging from 18 to 95 ). Third, income was assessed using an index of the ratio to poverty threshold. Fourth, employment was coded as unemployed, part-time or full-time. Finally, education was measured categorically, with 14 categories from $4^{\text {th }}$ grade to graduate school level.

The second set of covariates included five Acculturation Variables. First, English proficiency was constructed by averaging three self-report items respectively, rating speaking, reading, and writing fluencies (Cronbach's Alpha $=$ 0.97). Second, birthplace was classified as foreign-born (coded as 0 ) or US-born (coded as 1). Third, years in the US was categorized as $0-5,6-10,11-20$, and $\geq 21$ years, where the US-born participants were assigned the highest score to avoid missing data. Fourth, acculturation stress was assessed by a 10-item scale asking about acculturation stress (Vega et al., 1998), capturing strains associated with culture change (Cervantes, Padilla, and Salgado de Snyder, 1990). On this scale, immigrant respondents indicated "Yes" or "No" to each question. Examples of these questions included: "Do you feel guilty for leaving behind family and friends in your country of origin?" "Do you find it hard interacting with others because of difficulties you have with the English language?" and "Do you avoid seeking health service due to fear of immigration officials?" Yes is coded 1 and No is coded 0, and items are averaged to produce a total score (higher score indicates higher stress). The US born respondents were assigned the value 0 to avoid missing data. Cronbach's alpha for this 10 -item measure was 0.58 . Finally, Discrimination was assessed using 9 questions asking participants to rate how often they experienced various forms of discrimination in their day-to-day life (Gee, et al, 2007a). Example items include: "You receive poorer services than other people at restaurants or stores;" "You are called names or insulted;" and "People act as if they think you are not smart." The internal consistency for this 9-item scale was 0.91. Each item is rated on a 6-point scale $(1=$ never, $6=$ almost every day $)$, and items are averaged to produce a total score.

\subsection{Statistical methods}

Descriptive analyses were conducted to present the distribution of variables used in the regression analyses. We also used the previously developed weights (Alegria et al., 2004; Heeringa et al., 2004) in all analyses to correct for the sampling biases. Next, distributions of religious affiliations were presented. Thereafter, a set of hierarchical regression models were employed to test the effect of religious attendance on self-rating of mental health. Specifically, to examine whether religious involvement added significant predictive value regarding mental health above and beyond the effects of the known predictors, we included covariates (i.e., risk and confounding variables and key socio-demographics) in Step 1 in all these regressions. Then, in Step 2, religious attendance was entered into the two models, respectively. The set of regression analysis is a multiple regression because the outcome 
variable self-rating is a Likert scale measure. The estimated coefficient of each significant predictor shows the degree of an increase or a decrease in the outcome measure if the predictor is increased or decreased by one unit. Difference in chi-squares of Step 1 and Step 2 will indicate whether the newly added variables contributed to the power of the original sets of predictors.

\section{Results}

\subsection{Descriptive analysis}

The covariates, predictor and criterion variables used in the regression analyses are presented in Table 1 . As can be noted, most of the predictor variables have a good range and variability. Of the participants, $47 \%$ were male and $53 \%$ were female. Average age was 41 years, the mean of years of education was a little over 14 years, $79 \%$ were foreign-born, and most of them (68\%) were employed. Regarding the criterion variables, about one third each rated "good" and "very good" while one fifth rated "fair" for general mental health.

Concerning religious affiliation, almost a half of the Chinese indicated not being religious at all. Among those who did self-identify as religious, almost half of the religious Chinese also reported their religion as "Other". Unfortunately, as stated earlier, the public data provided by the NLAAS did not present information on the details within the "Other" religion category. Therefore, no information was discernable regarding Buddhist, Taoist, Hindu, Muslim, or Jewish Asian Americans. Table 2 shows religious affiliation and detailed attendance for Chinese Americans. Slightly more than half never attend religious services and $49 \%$ are not religious at all. Only $16.7 \%$ attend on average once a week or more. It appears Chinese Americans' religious affiliation and practice are different from Asian Americans as a whole (Ai et al., in press).

Table 3 shows the bivariate correlations between traditional covariates and religious attendance with self-rating of mental health. As can be seen, the bivariate correlation between religious attendance and self-rating of mental health is statistically significant, as are other traditional predictors such as income, years of immigration, discrimination and immigration stress, all of which are highly significant at bivariate level.

\subsection{Regression analyses}

As planned, one set of hierarchical multiple regression was performed to examine whether religious attendance added predictive power regarding self-reported mental health to that of the covariates (e.g., demographic, socioeconomic, and acculturation variables).

The first model tested the effect of religious attendance on self-rating of general mental health. As preplanned in Step 1, demographics and all other covariates were entered into the equation. In Step 2, religious attendance was added and the results are in Table 4 . The middle columns of Table 4 showed the results predicting self-rating of mental health from demographic, social, and cultural variables. The right side columns show the results for the regression that adds religious attendance.

Results showed that the Step 1 model significantly predicted self-rating of mental health for the sample. Specifically, being male correlates significantly to higher levels of mental health self-rating, increasing the level of self-rated mental health problems. Being male increased the level by 0.13 in self-rating mental health problems. English proficiency also improved the self-rating of mental health. One unit change of English proficiency increased the level of self-rating by 0.4 units. The rest of the predictors are not significant after controlling for each other, indicating that most of the variables are highly correlated with each other.

Table 4 shows that the Step 2 model was also significant. Religious attendance was a significant predictor as evidenced by the large $\mathrm{T}$ value. Religious attendance significantly predicted self-rating above and beyond the other predictors in Step 1. One unit of change in religious attendance was associated with people reporting 0.11 unit more in self-rating. The R square showed that $25 \%$ of the variance was explained by this model.

Finally, post hoc analyses showed religious attendance did not improve the predictive value for the diagnoses of either depression or anxiety over the past 12 months.

\section{Discussion}

This study used faith factors to predict mental health in a large representative sample of Chinese Americans. Using the national sample, our findings suggest that only a quarter of Chinese Americans hold mainstream religious faiths, though another quarter had perhaps more traditional Chinese or other Asian belief systems. Therefore, the literature may have overstated the proportion of Christians among all Chinese Americans (Yang, 1999). Most importantly, our finding demonstrates that religious service attendance can add incremental validity to the prediction of self-rated mental health in the Chinese American group. As such, it appears that the potentially protective role of religious involvement identified in African American and/or Caucasian American populations 
(Gorsuch, 1988; Mattis and Watson, 2009; Pargament, 1997) may also be in part applicable to Chinese Americans. Nevertheless, further analyses found no effect of religious attendance on the clinical diagnosis of depression and anxiety, over the past 12 months. In other words, the association manifested in this study may only reflect the perceived mental health by Chinese Americans, but does not involve their mental illnesses diagnosed by professionals.

To our knowledge, this study may be the first of its kind to use the national representative NLAAS dataset to examine the association between religious attendance and the mental health of Chinese Americans. The study supports an argument in the psychology of religion that religious involvement serves as a resource for people facing difficulties in their lives (Pargament, 1997). Because the only other protective factors are being male and having English proficiency, we believe this positive link between religious involvement and mental health identifies such involvement as a resource factor in the acculturation process. Interestingly, as in the earlier analysis of the whole Asian American group (Ai et al., in press), religious coping, as a more individual oriented manner, was not related to any outcomes in this study. Therefore, we suggest that social support, which derived from attending religious service in the collectivism-centered cultural tradition of Chinese Americans, may contribute positively to one's mental health (Guest, 2003; Hwang, Chun, Kurasaki, Mak, and Takeuchi, 2000). However, the more definitive answer will have to come from future longitudinal data in this population.

Given the low proportion of Chinese Americans who claim a mainstream Christian religion as their faith, it is very likely that the Judeo-Christian centered religious coping concept does not fit the collectivism-oriented Chinese culture very well, even though many Chinese Americans have lived in the US for generations. One reason for the low religious attendance and affiliation among Chinese Americans may be the difference in how Chinese people were reached by Christian missionaries in China. These findings suggest that religious factors, which have so far been understudied and under-recognized in Chinese American culture and health research, should be included in future studies and merit further study.

Specifically, religious attendance significantly added to the prediction of higher levels of self-rated mental health even after controlling for a pool of traditional predictors. However, it did not add predictive power to the clinical outcomes. This may also have implications for clinical and consulting psychological practice. Asian American immigrants receive a different quality of care from mental service providers compared to their US-born counterparts (Leong and Lau, 2001; US Department of Health and Human Services, 2001). Ethnic minorities were more likely than whites to have lower levels of trust and satisfaction with their physicians (Hunt, Gaba, and Lavizzo-Mourey, 2005). In general, Asian Americans seem particularly reluctant to seek services in response to their emotional distress. Even among Asian Americans with a probable mental disorder, only a small proportion (17\%) appears to seek services (US DHHS, 2001). Factors that reduce the use of mental health-related services include cultural barriers such as stigma, loss of face, causal beliefs (Leong and Lau, 2001) and culturally unresponsive services (e.g., a lack of match in language, ethnicity, and/or cross-cultural understanding; Sue, Fujino, Hu, Takeuchi, and Zane, 1991). It is critical for health care providers to recognize and understand the importance of culturally sensitive treatment for ethnic minorities. Such treatment approaches are necessary in order to eliminate disparities in physical and mental health (Ngo-Metzger et al., 2003).

Several limitations in this research should be noted. First, this study was based on a cross-sectional sample and was not an intervention study. Therefore, our findings do not inform causality. Despite the fact that previous small studies indicated similar associations between religious involvement and the protection of some Asian Americans, it is arguable that Chinese Americans who were less depressed could attend service more frequently. Longitudinal studies must address these questions. Second, despite the use of DSM-IV criteria, the diagnoses in this survey could not be considered clinical because they were derived from telephone interviews. Third, the available measures of religious involvement, adapted from the national database of mostly mainstream populations, do not fit well with research on faiths of Asian origin. This is important since Asian-specific faiths are a key part of the cultural make-up of many Chinese Americans. Finally, in relation to the third limitation, our analyses of the representative data in the NLAAS (Alegria et al., 2004) found that about a quarter of Chinese Americans (half of those religious) selected the "Other" category for their religious preference, whereas half of them chose the "No Religion" category. It seems likely that the beliefs and practices of many Chinese Americans who practice Asian-based faiths were limited within one of these two categories. Further waves of this national survey should address these issues.

Despite these limitations, our study demonstrates the importance of examining faith patterns in Chinese Americans with respect to their impact on mental health. Future research should include more rigorous variables and investigate their unique contributions to the improvement of mental health in Chinese Americans. In particular, such studies should also examine differences concerning the Asian-born faiths in relation to mental health. Given 
the current findings, faith factors appear to represent potential resources for Chinese Americans and should be further studied.

\section{References}

Ai, A. L. (2000). Spiritual well-being, population aging, and a need for improving practice with the elderly: A psychosocial account. Social Thought: Journal of Religion in the Social Services, 19(3), 1-21.

Ai, A. L. (2006). Daoist spirituality and philosophy: Implications for holistic health, aging, and longevity. In E. R. Mackenzie and B. Rakel (Eds.). Holistic approaches to health aging: Complementary and alternative medicine for older adults. New York, NY: Springer, 149-160.

Ai, A. L. (2010). Qigong. In M. S. Micozzi (Ed.). Fundamentals of complementary \& integrative medicine, $\left(4^{\text {th }}\right.$ Edition, pp. 418-436). St Louis, MO: Elsevier Health Sciences.

Ai, A. L. and McCormick, T. R. (2010). Increasing diversity of Americans' faiths alongside Baby Boomers' aging: Implications for health chaplains, intervention. Journal of Health Care Chaplaincy, 16(1), 22-39. http://dx.doi.org/10.1080/08854720903496126

Ai, A. L., Bjorck, J. P., Huang, B. and Appel, H. B. (2011). Asian American spirituality and religion: Inherent diversity, uniqueness, and long-lasting psychological influences. In K. Pargament, J. Exline, \& J. Jones (Eds). The APA Handbook of Psychology, Religion, and Spirituality, Vol. I,. Washington, DC: American Psychological Association.

Ai, A. L., Ladd, K. L., Peterson, C., Cook, C., Shearer, M. and Koenig, H. G. (2010). Long-term adjustment after surviving open-heart surgery: The effect of using prayer for coping replicated in a prospective design. The Gerontologists, 50, 798-809.

Ai, L. A., Hopp, F., Tice, T. N. and Koenig, H. (in press). Enhanced existential relationship in light of eudaemonic tradition and religious coping of middle-aged and older cardiac patients. Journal of Health Psychology.

Alegria, M., Takeuchi, D., Canino, G., Duan, N., Shrout, P., Meng, X. L. and Gong, F. (2004). Considering context, place and culture: The National Latino and Asian American Study. International Journal of Methods in Psychiatric Research, 13(4), 208-220. http://dx.doi.org/10.1002/mpr.178

Bjorck, J. P., Lee, Y. S. and Cohen, L. H. (1997). Control beliefs and faith as stress moderators for Korean-versus Caucasian-American Protestants. American Journal of Community Psychology, 25, 61-72. http://dx.doi.org/10.1023/A:1024645824829

Bjorck, J.P., Cuthbertson, W., Thurman, J. and Lee, Y. S. (2001). Ethnicity, coping, and distress among Korean-, Filipino-, and Caucasian-Americans. Journal of Social Psychology, 14, 421-42. http://dx.doi.org/10.1080/00224540109600563

Cervantes, R. C., Padilla, A. M. and Salgado de Snyder, N. (1990). Reliability and validity of the Hispanic Stress Inventory. Hispanic Journal of Behavioral Sciences, 12, 76-82. http://dx.doi.org/10.1177/07399863900121004

Chan, S. (1991). Asian Americans: An interpretive history. Boston, MA: Twayne.

Chen, T. (1940). Emigrant communities in South China. New York, NY: Institute of Pacific Relations.

Cohen, A. B. and Hill, P. C. (2007). Religion as culture: Religious individualism and collectivism among American Catholics, Jews, and Protestants. Journal of Personality, 75, 709-742. http://dx.doi.org/10.1111/j.1467-6494.2007.00454.x

Coruh, B., Ayele, H., Pugh, M. and Mulligan, T. (2005). Does religion activity improve health outcomes? A critical review of the recent literature. The Journal of Science and Healing, 1(3), 186-191. http://dx.doi.org/10.1016/j.explore.2005.02.001

Fiala, W. E., Bjorck, J. P. and Gorsuch, R. (2002). The religious support scale: Construction, validation, and cross-validation. American Journal of Community Psychology, 30(6), 761-786. http://dx.doi.org/10.1023/A:1020264718397

Fong, R. (2000). A history of Asian Americans. In F. M. Furuto, R. Biswas, D.K. Chung.

Furuto, S. M. and Murase, K. (1992). Asian Americans in the future. In S.M. Furuto, R. Biswas, D.

Galanter, M. (2006). Spirituality and addiction: A research and clinical perspective. American Journal of Addiction, 15(4), 286-292. http://dx.doi.org/10.1080/10550490600754325

Gee, G. C., Spencer, M. S., Chen, J. and Takeuchi, D. T. (2007a). A nationwide study of discrimination and 
chronic health conditions among Asian Americans. American Journal of Public Health, 97, 1275-1282. http://dx.doi.org/10.2105/AJPH.2006.091827

Gee, G. C., Spencer, M. S., Chen, J., Yip, T. and Takeuchi, D. T. (2007b). The association between self-reported racial discrimination and 12-month DSM-IV mental disorders among Asian Americans nationwide. Social Science Medicine, 64(10), 1984-1996. http://dx.doi.org/10.1016/j.socscimed.2007.02.013

George, L. K., Ellison, C. G. and Larson, D. B. (2002). Explaining the relationships between religious involvement and health. Psychological Inquiry, 13(3), 190-200. http://dx.doi.org/10.1207/S15327965PLI1303_04

Gorsuch, R. L. (1988). Psychology of religion. Annual Review of Psychology, 39, 201-221. http://dx.doi.org/10.1146/annurev.ps.39.020188.001221

Groth-Marnat, G. (1992). Buddhism and mental health: A comparative analysis. In J.F. Schumaker (Ed.), Religion and mental health (pp. 270-280). New York, NY: Oxford University Press.

Guest, K. J. (2003). God in Chinatown: Religion and survival in New York's evolving immigrant community. New York, NY: New York University Press.

Heeringa, S., Wagner, J., Torres, M., Duan, N., Adams, T. and Berglund, P. (2004). Sample designs and sampling methods for the Collaborative Psychiatric Epidemiology Studies (CPES). International Journal of Methods in Psychiatric Research, 13, 221-240. http://dx.doi.org/10.1002/mpr.179

Herrick, C. A. and Brown, H. N. (1998). Underutilization of mental health services by Asian Americans residing in the United States. Issues in Mental Health Nursing, 19(3), 225-240. http://dx.doi.org/10.1080/016128498249042 Humphrey, P. (1982). Islam in China Today. Religion, State, and Society, 10(2), 168-177.

Hwang, W. C, Myers, H. F. and Takeuchi, D. T. (2000). Psychosocial predictors of first-onset depression in Chinese Americans. Social Psychiatry and Psychiatric Epidemiology, 35, 133-145. http://dx.doi.org/10.1007/s001270050196

Hwang, W. C., Chun, C. A., Kurasaki, K., Mak, W. and Takeuchi, D. T. (2000). Factor validity of scores on a social support and conflict measure among Chinese Americans. Educational and Psychological Measurement, 60, 808-816. http://dx.doi.org/10.1177/00131640021970790

Koenig, H. G., McCullough M. and Larson, D. B. (2001). Handbook of religion and health. New York, NY: Oxford University Press. http://dx.doi.org/10.1093/acprof:oso/9780195118667.001.0001

Lam, W. A. and McCullough, L. B. (2000). Influence of religious and spiritual values on the willingness of Chinese-Americans to donate organs for transplantation. Clinical Transplantation, 14, 449-456. http://dx.doi.org/10.1034/j.1399-0012.2000.140502.x

Lee, E. K. and Chan, K. (2009). Religious/spiritual and other adaptive coping strategies among Chinese American older immigrants. Journal of Gerontological Social Work, 52(5), 517-533. http://dx.doi.org/10.1080/01634370902983203

Leong, F. T. L. and Lau, A. S. L. (2001). Barriers to providing effective mental health services to Asian Americans. Mental Health Services Research, 3(4), 201-214. http://dx.doi.org/10.1023/A:1013177014788

Mattis, J. S. and Watson, C. R. (2009). Religion and Spirituality. In H.A. Neville, B. M. Tynes, \& S. O. Utsey (Eds.), Handbook of African American psychology (pp. 91-102). Thousand Oaks, CA: Sage Publications.

Murray, C. J. and Lopez, A. D. (1996). The global burden of disease: A comprehensive assessment of mortality and disability from diseases, injury, and risk factors in 1990 and projected to 2020. Cambridge, MA: Harvard School of Public Health.

Neubauer, A. (2009). Mediaevil Jewish chronicles and chronological notes (1895). Whitefish, MT: Kessinger. (Original work published 1895).

Ngo-Metzger, Q., Massagli, M. P., Clarridge, B. R., Manocchia, M., Davis, R. B., Iezzoni, L. L. and Phillips, R. S. (2003). Linguistic and cultural barriers to care: Perspectives of Chinese and Vietnamese immigrants. Journal of General Internal Medicine, 18, 44-52. http://dx.doi.org/10.1046/j.1525-1497.2003.20205.x

Pargament, K. I. (1997). The psychology of religion and coping: Theory, research, and practice. New York, NY: Guilford Press.

Pargament, K. I., Koenig, H. G. and Perez, L. M. (2000). The many methods of religious coping: Development and initial validation of the RCOPE. Journal of Clinical Psychology, 56, 519-543. http://dx.doi.org/10.1002/(SICI)1097-4679(200004)56:4<519::AID-JCLP6>3.0.CO;2-1 
Pargament, K. I., Magyar-Russell, G. M. and Murray-Swank, N. A. (2005). The sacred and the search for significance: Religion as a unique process. Journal of Social Issues, 61(4), 665-687. http://dx.doi.org/10.1111/j.1540-4560.2005.00426.x

Passel, J.S. and Cohn, D. (2008). Immigration to play lead role in future U.S. growth. [Online] Available: http://pewresearch.org/pubs/729/united-states-population-projections

Peterson, C. and Seligman, M. E. P. (2004). Character strengths and virtues: A handbook and Classification (pp. 33-52). New York, NY: American Psychological Association \& Oxford University Press.

Powell, L. H., Shahabi, L. and Thoreson, C. E. (2003). Religion and spirituality: Linkages to physical health. American Psychologist, 58(1), 36-52. http://dx.doi.org/10.1037/0003-066X.58.1.36

Smith, T. B., McCullough, M. E. and Poll, J. (2003). Religiousness and depression: Evidence for a main effect and the moderating influence of stressful life events. Psychological Bulletin, 129(4), 614-636. http://dx.doi.org/10.1037/0033-2909.129.4.614

Spence, J. D. (1996). God's Chinese son: The Taiping heavenly kingdom of Hong Xiuquan. New York, NY: W.W. Norton and Company.

Sue, A., Sue, D. W., Sue, L. and Takeuchi, D. T. (1995). Psychopathology among Asian Americans: A model minority. Cultural Diversity Mental Health, 1, 39-51. http://dx.doi.org/10.1037/1099-9809.1.1.39

Sue, S., Fujino, D. C., Hu, L-T., Takeuchi, D. T. and Zane, W. N. S. (1991). Community mental health services for ethnic minority groups: A test of the cultural responsiveness hypothesis. Journal of Consulting and Clinical Psychology, 59(4), 533-540. http://dx.doi.org/10.1037/0022-006X.59.4.533

Takeuchi, D. T., Chung, R. C. Y., Lin, K. M., Shen, H., Kurasaki, K., Chun, C. and Sue, S. (1998). Lifetime and twelve-month prevalence rates of major depressive episodes and dysthymia among Chinese Americans in Los Angeles. American Journal of Psychiatry, 155, 1407-1414.

Townsend, M., Kladder, V., Ayele, H. and Mulligan, T. (2002). Systematic review of clinical trials examining the effects of religion on health. Southern Medical Journal, 95(12), 1429-1434.

US Census Bureau. [Online] Available: http://www.census.gov/Press-Release/www/releases/archives/population/001720.html (August 28, 2009)

US Department of Health and Human Services, (2001). Mental health: culture, race, and ethnicity-A supplement to mental health: A report of the surgeon general. Rockville, MD: Author.

Vega, W. A., Kolody, B., Aguilar-Gaxiola, S., Alderete, E., Catalano, R. and Caraveo-Anduaga, J. (1998). Lifetime prevalence of DSM-III-R psychiatric disorders among urban and rural Mexican Americans in California. Archives of General Psychiatry, 55, 771-778. http://dx.doi.org/10.1001/archpsyc.55.9.771

Verhoeven, M. J. (1998). Americanizing the Buddha, Paul Carus and the transformation of Asian thought. In C. S. Prebish, and K. K. Tanaka (Eds.). The faces of Buddhism in America (pp.207-227). Berkeley, CA: University of California Press.

Woodruff, P. (2001). Reverence: Renewing a forgotten virtue. New York, NY: Oxford University Press.

Yang, F. (1999). Chinese Christians in America: Conversion, assimilation, and adhesive identities. University Park, PA: Penn State Press. 
Table 1. Means, standard deviations and ranges of the variables of interest $(\mathrm{N}=600)$ : NLAAS 2002-2003

\begin{tabular}{lllll}
\hline \multicolumn{1}{c}{ Predictors } & Mean & SD & Minimum & Maximum \\
\hline $\begin{array}{llll}\text { Demographic variables } \\
\text { Sex(male =1) }\end{array}$ & & & & \\
Age (years) & 0.47 & 0.50 & 0 & 1 \\
Income & 41.59 & 14.02 & 18 & 85 \\
Employment & 6.23 & 5.34 & 0 & 17 \\
Education (years) & 2.36 & 0.93 & 1 & 3 \\
Acculturation variables & 14.06 & 3.14 & 4 & 17 \\
English proficiency & & & & \\
Birthplace (US-born =1) & 2.61 & 1.27 & 1 & 4 \\
Years in US (categorical) & 0.21 & 0.41 & 0 & 1 \\
Acculturation stress & 3.28 & 1.27 & 1 & 5 \\
Discrimination & 0.21 & 0.18 & 0 & 1 \\
Religious attendance & 1.78 & 0.66 & 1 & 6 \\
$\quad$ Criterion & 1.86 & 1.25 & 1 & 5 \\
Self-rating mental health & 3.62 & & & \\
\hline SD & & 1.00 & 1 & 5 \\
\hline
\end{tabular}

$\mathrm{SD}=$ standard deviation

Table 2. Religious affiliation and attendance of Chinese Americans and Asian Americans: NLAAS 2002-2003

\begin{tabular}{lll}
\hline \multicolumn{1}{c}{ Religious affiliation (\%) } & Chinese & Asian American Overall \\
\hline Protestant & 20.4 & 21.3 \\
Catholic & 7.8 & 24.8 \\
Other religion & 22.7 & 32.5 \\
None & 49.1 & 21.3 \\
$\quad$ Attendance frequency (\%) & & \\
Never & 60.6 & 27.8 \\
Less than once a month & 19.0 & 22.4 \\
One to three times a month & 6.9 & 14.1 \\
Once a week & 9.0 & 25.3 \\
More than once a week & 4.5 & 10.5 \\
\hline
\end{tabular}

Table 3. Bivariate correlations among predictor variables and self-rating of mental health: NLAAS 2002-2003

\begin{tabular}{lcc}
\hline \multicolumn{1}{c}{ Predictors } & Correlations with Self-rating & P \\
\multicolumn{1}{c}{$\begin{array}{c}\text { Demographic variables } \\
\text { Gender (male =1) }\end{array}$} & 0.178 & 0.000 \\
Age & -0.162 & 0.000 \\
Income & 0.217 & 0.000 \\
Employment & 0.106 & 0.000 \\
Education & 0.302 & 0.000 \\
$\quad$ Acculturation variables & & \\
English proficiency & 0.456 & 0.000 \\
Birthplace (US-born =1) & 0.222 & 0.000 \\
Years in US (categorical) & 0.172 & 0.000 \\
Acculturation stress & -0.218 & 0.00 \\
Discrimination & 0.113 & 0.006 \\
Religious attendance & 0.128 & 0.002 \\
\hline
\end{tabular}


Table 4. Multiple regression results predicting self-rating of mental health: NLAAS 2002-2003

Step1

Step2

\section{Predictors}

Demographic variables

Gender $($ male $=1)$

Age

$0.135 * * *$

0.07

0.069

0.037

0.065

$$
\begin{gathered}
0.412 * * * \\
0.042 \\
-0.009 \\
0.027 \\
-0.036
\end{gathered}
$$

Discrimon

Religious attendance

R square

${ }^{*} \mathrm{p}<0.05, * * \mathrm{p}<0.01, * * * \mathrm{p}<0.001$.
$0.142 * * *$

0.047

0.078

0.038

0.045

$0.403 * * *$

0.041

$-0.035$

0.017

$-0.033$

$0.111 * * *$

0.245 